\title{
The Effect of Retrospectively Perceived Parental Bonding on Resilience in Adulthood
}

\author{
Monika Skeryte-Kazlauskiene ${ }^{1}$, Egle Mazulyte ${ }^{1}$, Jonas Eimontas ${ }^{1}$, Evaldas Kazlauskas ${ }^{1} \&$ Danute Gailiene ${ }^{1}$ \\ ${ }^{1}$ Vilnius University, Vilnius, Lithuania \\ Correspondence: Monika Skeryte-Kazlauskiene, Vilnius University, Universiteto str.9/1, Vilnius, 01513, \\ Lithuania. Tel: 370-5266-7605. E-mail: mskeryte@yahoo.com
}

Received: March 29, 2015

Accepted: April 2, 2015

Online Published: May 29, 2015

doi:10.5539/ijps.v7n2p174

URL: http://dx.doi.org/10.5539/ijps.v7n2p174

\begin{abstract}
Parenting is reported to be a crucial factor for children's resilience; however, it is still unknown whether the effect of parental bonding in childhood persists on resilience later on in adulthood. The aim of our research is to evaluate the effect of retrospectively perceived parental bonding on adult resilience and its change in adulthood; we aim to study parental care, authoritarianism and behavioral control as the dimensions of parental bonding. A total of 745 adults from 18 to 81 years of age $(M=44.54, S D=17.96)$ completed Lithuanian versions of the abbreviated Parental Bonding Instrument (PBI) and the 14-Item Resilience Scale (RS-14). Results show that there is a small though significant effect of parental bonding on resilience: the importance of parental care persists even into older age, but the significance of authoritarianism diminishes with age.
\end{abstract}

Keywords: adulthood, authoritarianism, care, control, parental bonding, protectiveness, resilience

\section{Introduction}

Various studies with different research strategies confirm that parenting qualities are crucial for resilience in children (Masten, 2001). The relation of parenting and resilience is well supported with evidence from a child's life trajectories, but there is a lack of empirical evidence, whether this relation of parental qualities and resilience is retained in adulthood or if it changes during the life span, since later in life other factors moderate the process of resilience and the importance of this parent-child connection might diminish.

Individuals experience various levels of stress, trauma, threats, and adversities in their life, but there is also some degree of psychological resilience, which is common for all individuals (Masten, 2001). Resilience moderates the negative impact of stress, traumas or adverse situations (Ahern, Kiehl, Lou Sole, \& Byers, 2006) and ensures normal development even in the face of severe adversity. As there are various degrees of risk and adversity, there are also various potential qualities of the individual and the environment, which might moderate the effect of adversities, increasing resilience and protecting the individual (Masten, 2001).

Positive aspects of the family are listed as one set of external environmental factors of resilience (Kumpfer, 1999; Luthar, Cicchetti, \& Becker, 2000). Various studies indicate that parenting practices mediate children's vulnerability to trauma exposure and post-traumatic symptoms (review by Gewirtz, Forgatch, \& Wieling, 2008), positive parenting predicts good outcomes across competence domains, even in the context of severe, chronic adversity (Masten, 2001; Masten et al., 1999). A longitudinal study by Masten et al. (1999) showed the fundamental importance of parenting for children's and youths' adaptation in comparison to other risk and protective factors.

In addition to specific parenting practices, having a good relationship with a parent is mentioned as a family protective factor for positive child adjustment across social, emotional, and academic domains (Vanderbilt \& Shaw, 2008). Research supports the separation of warmth and control dimensions of parent-child relations (Suchman, Rounsaville, DeCoste, \& Luthar, 2007). The dimension of warmth or care forms a continuum of parental acceptance and rejection (Rohner, Khaleque, \& Cournoyer, 2005), which "has to do with the quality of the affectional bond between parents and their children, and with the physical and verbal behaviors parents use to express these feelings" (Rohner et al., 2005, p. 305.). The control dimension of parental bonding has more than one form, according to the multiple-forms approach. One form of control forms a continuum between parental controlling behavior and the support of autonomy (Grolnick, 2002); it is called authoritarianism, 
characterized by parental pressure, intrusiveness, and dominance in relation to children (Grolnick \& Pomerantz, 2009). Other forms of control can be operationalized as behavioral control-monitoring of children's behavior, involvement in making decisions (Grolnick \& Pomerantz, 2009), which provides guidance and is important for child development. We find these three dimensions of parental bonding - care, authoritarianism, and behavior control-important and include them in our research.

Though there are many studies on parenting and resilience, most of them (Masten et al., 1999; Vanderbilt \& Shaw, 2008) are focused on children and adolescents with a lack of studies among adults, especially older adults. There is evidence that other risk and protective factors intervene and affect the resilience of the individual in their life span (Masten, 2001). However, it is not clear, whether the effect of parental bonding on resilience persists or changes during adulthood. The aim of our research is to evaluate the effect of retrospectively perceived parental bonding on adult resilience and its change in adulthood.

\section{Method}

\subsection{Participants}

The participants of the study were 745 adults aged between 18 and 81 years $(M=44.54 ; S D=17.96), 41 \%$ men $(n=303)$ and $59 \%$ women $(n=442)$. Participants were selected according to quota sampling to meet the criteria of education, place of residence (urban or rural), gender and age to correspond to the diversities of the Lithuanian population, according to Lithuanian population census data. From the total sample $30 \%$ were from rural areas ( $n$ $=226$ ), $28 \%$ lived in smaller cities $(n=210)$, and $41 \%(n=308)$ were from the largest cities (from 0.5 mil. to 0.1 mil. of residents) of Lithuania; $15 \%(n=114), 38 \%(n=280)$ and $46 \%(n=345)$ of participants had low, medium, and high educational levels respectively; 56\% $(n=417)$ were actively working, $19 \%(n=142)$ were studying and $23 \%(n=169)$ of the participants were retired; $49 \%(n=362)$ were married and $31 \%(\mathrm{n}=229)$ single. Participants were predominantly from an ethnic Lithuanian background (81\%).

\subsection{Procedures}

Data for this study was collected through in-person interviews at participants' homes or working places; the study was a part of a larger project. Interviews were carried out by trained research assistants (undergraduate and postgraduate psychology students) and $\mathrm{PhD}$ level university researchers. Informed consent was obtained from all participants before the data gathering. The questionnaires were completed mostly by the participants themselves, researchers read the questionnaires for the participants to respond in cases of poor eyesight or poor reading abilities. Some participants have not completed the Parental Bonding Instrument because of the absence of their mother $(3 \%)$ or father $(9 \%)$ in childhood; their data was eliminated only from the relevant analyses.

\subsection{Measures}

A Lithuanian version of the 14-item Resilience Scale (RS-14) (Wagnild, 2009) was used to identify the degree of individual resilience (Mazulyte et al., 2014). RS-14 consists of 14 items (e.g. I usually manage one way or another); all items are scored on a 7 point Likert type scale with two anchor points: 1-totally disagree, 7-totally agree. All the items of the scale are worded positively and the score is summed; higher scores reflect higher resilience. The scale is based on grounded theory research (Wagnild \& Young, 1993), and various studies support its validity and reliability (Ahern et al., 2006; Wagnild, 2009). The internal validity of the Lithuanian version of RS-14 had a Cronbach's $a$ value of .87 (Mazulyte et al., 2014).

Perceived parental bonding was measured with a Lithuanian abbreviated version of the Parental Bonding Instrument (PBI) (Parker, Tupling, \& Brown, 1979). PBI is a self-report questionnaire developed to measure the subjective experience of being parented to the age of 16 years (Parker et al., 1979). It is used to measure parenting style in a range of clinical and non-clinical subject groups (Wilhelm, Niven, Parker, \& Hadzi-Pavlovic, 2004); there are separate scales to evaluate mother's and father's parenting behavior. All participants of the study were over 18 years old, so all the evaluations of the participants were retrospective. There are a few possible ways to compute factors comprising the PBI. We used the three factor model of care, protectiveness (behavioral control), and authoritarianism, proposed by Kendler (1996), and empirically confirmed in a study by Tsaousis, Macha and Giovazolias (2012). The original PBI scale comprises of 25 items, an abbreviated version of the PBI, constructed by the authors of the article, consisted of 9 items. The abbreviated version was developed according to Kendler's three-factor solution and the parameter estimates of each item (Tsaousis et al., 2012). The three items with the highest parameter estimates were selected for each factor: care ("Spoke to me in a warm and friendly voice", "Enjoyed talking things over with me", "Frequently smiled at me"), protectiveness ("Tried to control everything I did", "Tried to make me feel dependent on her/him", "Was overprotective of me"), and authoritarianism (reversed items: "Liked me to make my own decisions", "Let me decide things for myself", 
"Gave me as much freedom as I wanted"). All items were scored on a 4-point Likert type scale from 0 (very unlikely) to 3 (very likely), the scores were summed. Lithuanian abbreviated version of the PBI showed adequate internal consistency, the Cronbach's alpha values for different factors in this study ranged from .69 to .83 .

\subsection{Data Analysis}

Bivariate correlations were used to examine relations between variables. Separate hierarchical analyses were calculated for every parental bonding factor to examine the unique effects of each parameter on resilience. In order to evaluate the effect of age, as well as the effect of interaction of age with parental bonding, three steps were included in all regression analyses: age, parental bonding factor and interaction between age and parental bonding factor. Analyses were conducted using IBM SPSS Statistics 21 software. Skewness and kurtosis of all study variables were acceptable.

\section{Results}

\subsection{Primary Correlational Analysis}

There was no statistically significant increase or decrease of resilience related with age ( $r=.06)$ (see Table 1). Two of the parental bonding factors were valued differently in relation with the age of participants: the older the participants, the more parental care and protectiveness from the father they reported $(r=.16)$. Since the age of participants was related to the evaluations of parental bonding, we included Age and Age $\times$ Parental bonding interaction in further analyses.

Table 1. Intercorrelations among age, resilience and parental bonding variables

\begin{tabular}{llllllll}
\hline & 1 & 2 & 3 & 4 & 5 & 6 & 7 \\
\hline 1. Age & - & & & & & & \\
2. Resilience & .06 & - & & & & & \\
3. M care & -.03 & $.23^{* * *}$ & - & & & & \\
4. M protectiveness & .06 & .01 & .03 & - & & & \\
5. M authoritarianism & -.05 & $-.16^{* * *}$ & $-.54^{* * *}$ & $.24^{* *}$ & - & & \\
6. F care & $.16^{* * *}$ & $.15^{* *}$ & $.35^{* * *}$ & $.10^{* *}$ & $-.20^{* * *}$ & - & \\
7. F protectiveness & $.16^{* * *}$ & .06 & $.19^{* * *}$ & $.51^{* * *}$ & -.02 & $.21^{* * *}$ & - \\
8. F authoritarianism & $-.10^{*}$ & $-.20^{* * *}$ & $-.28^{* * *}$ & -.01 & $.42^{* * *}$ & $-.61^{* * *}$ & .01 \\
\hline
\end{tabular}

Note. $\mathrm{M}=$ mother; $\mathrm{F}=$ father.

${ }^{*} p<.05, * * p<.01, * * * p<.001$ (two-tailed).

There were statistically significant correlations between resilience and parental bonding. Resilience was positively related to the care factor ( $r=.23$ mother's care, $r=.15$ father's care), and negatively related to the authoritarianism factor ( $r=-.16$ mother's authoritarianism, $r=-.20$ father's authoritarianism). Resilience was not related to the protectiveness factor neither for the mother's, nor for the father's evaluations $(r=.01$, and $r=.06$ respectively).

Parental bonding factors were correlated intersubjectively (see Table 1). The evaluations of mother's and father's bonding were similar $(\mathrm{r}=.35$ for care, $\mathrm{r}=.51$ for protectiveness, $\mathrm{r}=.42$ for authoritarianism). The care factor was negatively related with the authoritarianism factor for both parents ( $r$ from -.20 to -.61). Mother's protectiveness was positively related to mother's authoritarianism $(r=.24)$, but not with mother's care $(r=.03)$. Father's protectiveness was associated with father's care $(r=.21)$, but not associated with father's authoritarianism $(r=.01)$. Based on these correlations, we further analyzed the prediction of resilience by each parental bonding factor separately.

\subsection{Resilience Prediction Analysis}

Hierarchical regression analyses were computed to predict resilience from parental bonding (see Table 2); it showed a small but significant effect of parental care and parental authoritarianism (mother's care $R^{2}=.06, F(1$, 714) $=40.20, p<.001$; father's care $R^{2}=.03, F(1,670)=15.95, p<.001$; mother's authoritarianism $R^{2}=.03, F(1$, $714)=19.40, p<.001$, father's authoritarianism $\left.R^{2}=.04, F(1,669)=26.16, p<.001\right)$. There was no significant effect 
of parental protectiveness on resilience. No significant effect of age per se was found on resilience. There were small but significant effects of the Age $\times$ Parenting factor interaction for the authoritarianism factor $\left(R^{2}=.03, F(1\right.$, $713)=3.84, p=.050$ for mother's scales, and $R^{2}=.05, F(1,668)=4.12, p=.043$ for father's scales), but there was no effect of the Age $\times$ Parenting factor interaction for care or protectiveness factors.

Table 2. Summary of hierarchical regression analyses predicting resilience

\begin{tabular}{lllll}
\hline Steps of regressions & $R$ & $\Delta R^{2}$ & $\beta$ & $t$ \\
\hline Age & .05 & .003 & .06 & 1.68 \\
Mother's care & .24 & $.053^{* *}$ & .23 & $6.33^{* *}$ \\
Age $\times$ Mother's care & .24 & .000 & -.002 & -0.07 \\
Age & .06 & .004 & .04 & 1.10 \\
Father's care & .17 & $.023^{* *}$ & .15 & $3.93^{* *}$ \\
Age $\times$ Father's care & .17 & .003 & -.05 & -1.32 \\
Age & .05 & .003 & .05 & 1.45 \\
Mother's protectiveness & .06 & .000 & .01 & 0.19 \\
Age $\times$ Mother's protectiveness & .07 & .002 & .05 & 1.25 \\
Age & .06 & .004 & .05 & 1.35 \\
Father's protectiveness & .08 & .003 & .05 & 1.28 \\
Age $\times$ Father's protectiveness & .08 & .000 & .02 & 0.52 \\
Age & .05 & .003 & -.05 & 1.34 \\
Mother's authoritarianism & .17 & $.026^{* *}$ & -.17 & $-4.54^{* *}$ \\
Age $\times$ Mother's authoritarianism & .19 & $.005^{*}$ & .07 & $1.96^{*}$ \\
Age & .06 & .004 & .04 & 1.15 \\
Father's authoritarianism & .20 & $.037^{* *}$ & -.19 & $-5.01^{* *}$ \\
Age $\times$ Father's authoritarianism & .22 & $.006^{*}$ & .08 & $2.03 *$ \\
\hline
\end{tabular}

Note. The $\beta$ and $t$ values are obtained at the final step of the analysis; ${ }^{*} \mathrm{p} \leq .05 ; * * \mathrm{p}<.001$.

\section{Discussion}

The current study examined the effect of retrospectively perceived parental bonding on resilience in adulthood. Results show that there is a relation between parental bonding and resilience in adulthood, but it depends on the estimated quality of parental bonding: the more care from the mother or father adults remembered when they were young, the more resilience they reported; if the father or mother was remembered as more authoritarian, the degree of resilience was reported to be smaller. Protectiveness, the third measured quality of parental bonding was not related to resilience in any way.

The age of participants was not related to resilience, but relations of parental bonding and age were found: older participants remembered more of their father's care and protection. As the age factor was included in the analyses, no direct effect of age on resilience was found, but there was a significant effect of the interaction of age and the authoritarianism factor. As the importance of parental care for resilience remains even in older age, the significance of authoritarianism diminishes with age; the older the person, the less significant authoritarian behavior of parents become for adults' resilience.

The results of the study support other studies (Masten, 2001; Rohner et al., 2005) and extend their findings into adult life. It is important to note that the degree of mother's or father's behavior, which shows affectional bonds between a parent and child, such as talking in a warm and friendly voice, frequent smiles, enjoying talking things over with the child, has importance not only in childhood, but also in adulthood and even in older age. The fact that the effect of authoritarian behavior, such as opposing autonomous decisions, or intrusiveness, diminishes with age, suggests that other factors might intervene and change the path to resilience. 
Results should be considered in the light of several limitations. There were major changes during the 20th century in Lithuania, when all participants grew up. Parenting itself and its evaluations might be sensitive to these cultural changes, as older participants report more of father's care and protectiveness: the oldest group was raised after the Second World War and the role of a father in the post war society in an occupied country might be different. Some longitudinal studies should be carried out to support our results. We did not evaluate the current communications status with parents - whether they are still alive, whether the relations are satisfying or poor, and so on. This aspect might also affect the retrospective evaluations of parental bonding. It is also important to remember, that the relations of parental bonding evaluations and resilience do not explain the cause and effect of these phenomenons, because of the bidirectional nature of the influence in living systems (Masten, 2001). It is possible that more resilient individuals were easy going in childhood and received more smiles from caregivers than the ones who were less resilient then and now. It is clear that longitudinal studies with a personality assessment would be valuable to further evaluate the relation between parental bonding and resilience.

In spite of the limitations of the study, the results contribute to the creation of preventive programs, as it once more reminds us of the importance of parental warmth, care, and respect for children's autonomy in childhood and adulthood.

\section{Acknowledgments}

This research is a part of a project funded by the European Social Fund under the Global Grant measure (VP1-3.1SMM-07-K-02-023), with the funding awarded to Danute Gailiene. We are grateful for all the participants who willingly took part in the study. We thank all the assistants who contributed with data collection. We appreciate Vilmante Pakalniskiene for statistical methodology guidance and Vincentas Giedraitis for linguistic guidance.

\section{References}

Ahern, N. R., Kiehl, E. M., Lou, S. M., \& Byers, J. (2006). A review of instruments measuring resilience. Issues in Comprehensive Pediatric Nursing, 29, 103-125. http://dx.doi.org/10.1080/01460860600677643

Gewirtz, A., Forgatch, M., \& Wieling, E. (2008). Parenting practices as potential mechanisms for child adjustment following mass trauma. Journal of Marital and Family Therapy, 34, 177-192. http://dx.doi.org/10.1111/j.1752-0606.2008.00063.x

Grolnick, W. S. (2002). The psychology of parental control: How well-meant parenting backfires. New York: Psychology Press.

Grolnick, W. S., \& Pomerantz, E. M. (2009). Issues and challenges in studying parental control: Toward a new conceptualization. Child Development Perspectives, 3, 165-170. http://dx.doi.org/10.1111/ j.1750-8606.2009.00099.x

Kendler, K. S. (1996). Parenting: A genetic-epidemiologic perspective. American Journal of Psychiatry, 153, 11-20. http://dx.doi.org/10.1176/ajp.153.1.11

Kumpfer, K. L. (1999). Factors and processes contributing to resilience: The resilience framework. In M. D. Glantz, \& J. L. Johnson (Eds.), Resilience and development: Positive life adaptations (pp. 179-222). New York: Kluwer Academic/Plenum Press.

Luthar, S. S., Cicchetti, D., \& Becker, B. (2000). The construct of resilience: A critical evaluation and guidelines for future work. Child Development, 71, 543-562. http://dx.doi.org/10.1111/1467-8624.00164

Masten, A. S. (2001). Ordinary magic: Resilience processes in development. American Psychologist, 56, 227-238. http://dx.doi.org/10.1037/0003-066X.56.3.227

Masten, A. S. et al. (1999). Competence in the context of adversity: Pathways to resilience and maladaptation from childhood to late adolescence. Development and Psychopathology, 11, 143-169. http://dx.doi.org/ $10.1017 /$ S0954579499001996

Mažulyte, E. et al. (2014). Trauma experience, psychological resilience and dispositional optimism: Three adult generations in Lithuania. Psichologija/Psychology, 49, 20-33. Retrieved from http://www.journals.vu.lt/ psichologija/article/view/3696/2654

Parker, G., Tupling, H., \& Brown, L. B. (1979). A Parental Bonding Instrument. British Journal of Medical Psychology, 52, 1-10. http://dx.doi.org/10.1111/j.2044-8341.1979.tb02487.x 
Rohner, R. P., Khaleque, A., \& Cournoyer, D. E. (2005). Parental acceptance-rejection: Theory, methods, cross-Cultural evidence, and implications. Ethos, 33, 299-334. http://dx.doi.org/10.1525/ eth.2005.33.3.299

Suchman, N. E., Rounsaville, B., DeCoste, C., \& Luthar, S. (2007). Parental control, parental warmth, and psychosocial adjustment in a sample of substance-abusing mothers and their school-aged and adolescent children. Journal of Substance Abuse Treatment, 32, 1-10. http://dx.doi.org/10.1016/j.jsat.2006.07.002

Tsaousis, I., Mascha, K., \& Giovazolias, T. (2012). Can parental bonding be assessed in children? Factor structure and factorial invariance of the Parental Bonding Instrument (PBI) between adults and children. Child Psychiatry \& Human Development, 43, 238-253. http://dx.doi.org/10.1007/s10578-011-0260-3

Vanderbilt, A. E., \& Shaw, D. S. (2008). Conceptualizing and re-evaluating resilience across levels of risk, time, and domains of competence. Clinical Child and Family Psychology Review, 11, 30-58. http://dx.doi.org/10.1007/s10567-008-0031-2

Wagnild, G. (2009). The Resilience Scale user's guide for the US English version of the Resilience Scale and the 14-Item Resilience Scale (RS-14).

Wagnild, G. M., \& Young, H. M. (1993). Development and psychometric evaluation of the Resilience Scale. Journal of Nursing Measurement, 1, 165-178.

Wilhelm, K., Niven, H., Parker, G., \& Hadzi-Pavlovic, D. (2005). The stability of the Parental Bonding Instrument over a 20-year period. Psychological Medicine, 35, 387-393. http://dx.doi.org/10.1017/ S0033291704003538

\section{Copyrights}

Copyright for this article is retained by the authors, with first publication rights granted to the journal.

This is an open-access article distributed under the terms and conditions of the Creative Commons Attribution license (http://creativecommons.org/licenses/by/3.0/). 